\title{
Shallow pressure sources associated with the 2007 and 2014 phreatic eruptions of Mt. Ontake, Japan
}

\author{
Akimichi Takagi and Shin'ya Onizawa
}

\begin{abstract}
We modeled pressure sources under Mount Ontake volcano, Japan, on the basis of global navigation satellite system (GNSS) observations of ground deformation during the time period including the 2007 and 2014 phreatic eruptions. The total change in volume in two sources below sea level in the period including the 2007 eruption was estimated from GNSS network observations to be $6 \times 10^{6} \mathrm{~m}^{3}$. Additionally, data from a GNSS campaign survey yielded an estimated volume change of $0.28 \times 10^{6} \mathrm{~m}^{3}$ in a shallower source just beneath the volcanic vents. The 2007 eruption may have been activated by magmatic activity at depth. During the 2014 eruption, the volume change at depth was very small. However, tiltmeter data indicated inflation from a shallow source that began 7 min before the eruption, representing a volume change estimated to be $0.38 \times 10^{6} \mathrm{~m}^{3}$. We infer that the potential for subsurface hydrothermal activity may have remained high after the 2007 eruption.
\end{abstract}

Keywords: Mt. Ontake, Phreatic eruption, Pressure source, GNSS, Tiltmeter

\section{Introduction}

Mount Ontake volcano, a 3067-m volcano in central Honshu Island, Japan, has had two phreatic eruptions in recent years that were accompanied by ground deformation. Even though a phreatic eruption does not produce lava, it can cause multiple casualties to hikers during the popular mountaineering seasons. For this reason, it is important to study the shallow pressure sources beneath active volcanoes that can produce phreatic eruptions.

A very small eruption in late March of 2007 resulted in no casualties; however, an eruption on September 27, 2014, killed 63 people. The 2014 eruption was an isolated phreatic eruption that created a small pyroclastic flow, but there was no ejecta or flow of lava. The eruption plume reached an estimated 10,000 $\mathrm{m}$ above sea level (Meteorological Research Institute 2016). The volume of the eruptive products was estimated to be $0.3-0.5 \times 10^{6} \mathrm{~m}^{3}$ dense rock equivalent (DRE) from a field survey conducted after the 2014 eruption (Maeno et al. 2016), but no obvious ground deformation was detected on the day of the eruption.

\section{*Correspondence: atakagi@mri-jma.go.jp}

Volcanology Research Department, Meteorological Research Institute,

Japan Meteorological Agency, 1-1 Nagamine, Tsukuba,

Ibaraki 305-0052, Japan
It is difficult to detect ground deformation prior to phreatic eruptions because they can occur without obvious magma migration. However, ground deformation caused by shallow pressure sources associated with phreatic or possible phreatic eruptions has been observed in some cases (e.g., Takagi 2013; Yoshida et al. 2012). In this paper, we report evidence on shallow pressure sources associated with the 2007 and 2014 eruptions of Mt. Ontake.

\section{Ground deformation before and after the 2007 eruption}

Mt. Ontake has been monitored since 1995 by a global navigation satellite system (GNSS) observation network deployed as part of GEONET, managed by the Geospatial Information Authority of Japan (GSI), and monitored independently since 2001 by the Japan Meteorological Agency (JMA) volcano observation network JMANET. In GEONET, a nationwide network, the distance between stations is about $20 \mathrm{~km}$. JMANET has only three stations at Mt. Ontake, but these are less than $8 \mathrm{~km}$ from the summit (Fig. 1).

The geodetic coordinates of GEONET stations are analyzed by GSI using precise ephemeris data, and they are generally provided in a form called the F3 final solution (Nakagawa et al. 2009). The JMANET system, which 


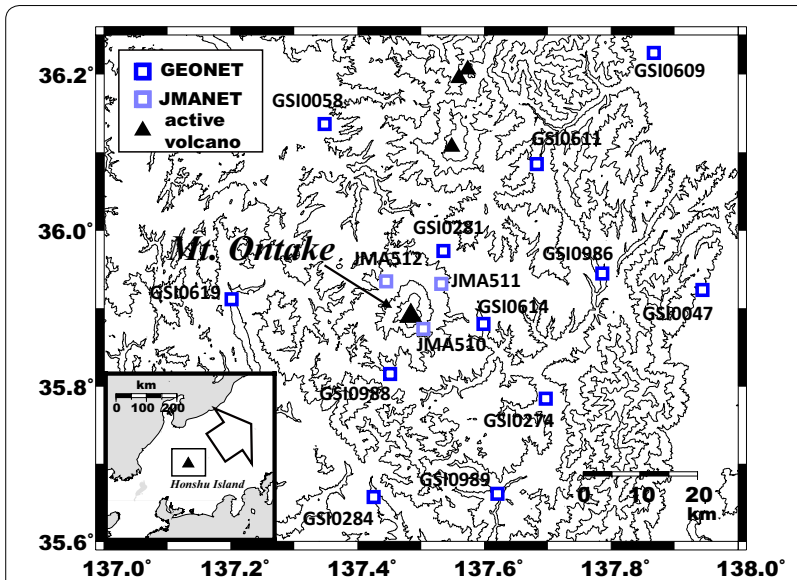

Fig. 1 Topographic map of Mt. Ontake showing locations of active volcanoes and GNSS sites. Blue squares show GEONET stations, aqua squares show JMANET stations, and solid triangles show active volcanoes. Contour interval is $500 \mathrm{~m}$. Inset map shows location of Mt. Ontake in central Honshu, Japan consists of single-frequency-receiver stations, except for JMA510, is independent from the nationwide GEONET system. The raw data of both JMANET and GEONET stations were analyzed so that coordinates based on JMANET were connected to GEONET. We recalculated the coordinate of JMA510 referred to GSI0614 and GSI0988 by double-frequency analysis, and we also did the coordinates of JMA511 and JMA512 referred to JMA510 by single-frequency analysis, using the GNSS analysis software Bernese Ver. 5.0 (Dach et al. 2007). The relative coordinates of the JMANET stations were connected to the F3 final solution of GEONET.

Figure 2 shows time series of the lengths of five baselines (shown in Fig. 3) around Mt. Ontake along with the daily number of volcanic earthquakes. Discontinuities resulting from antenna replacement have been corrected. The time series of all of the baselines include changes caused by the 2011 off the Pacific coast of Tohoku Earthquake, and those of some baselines include seasonal noise caused by weather. After the exclusion of these non-volcanic changes, most of

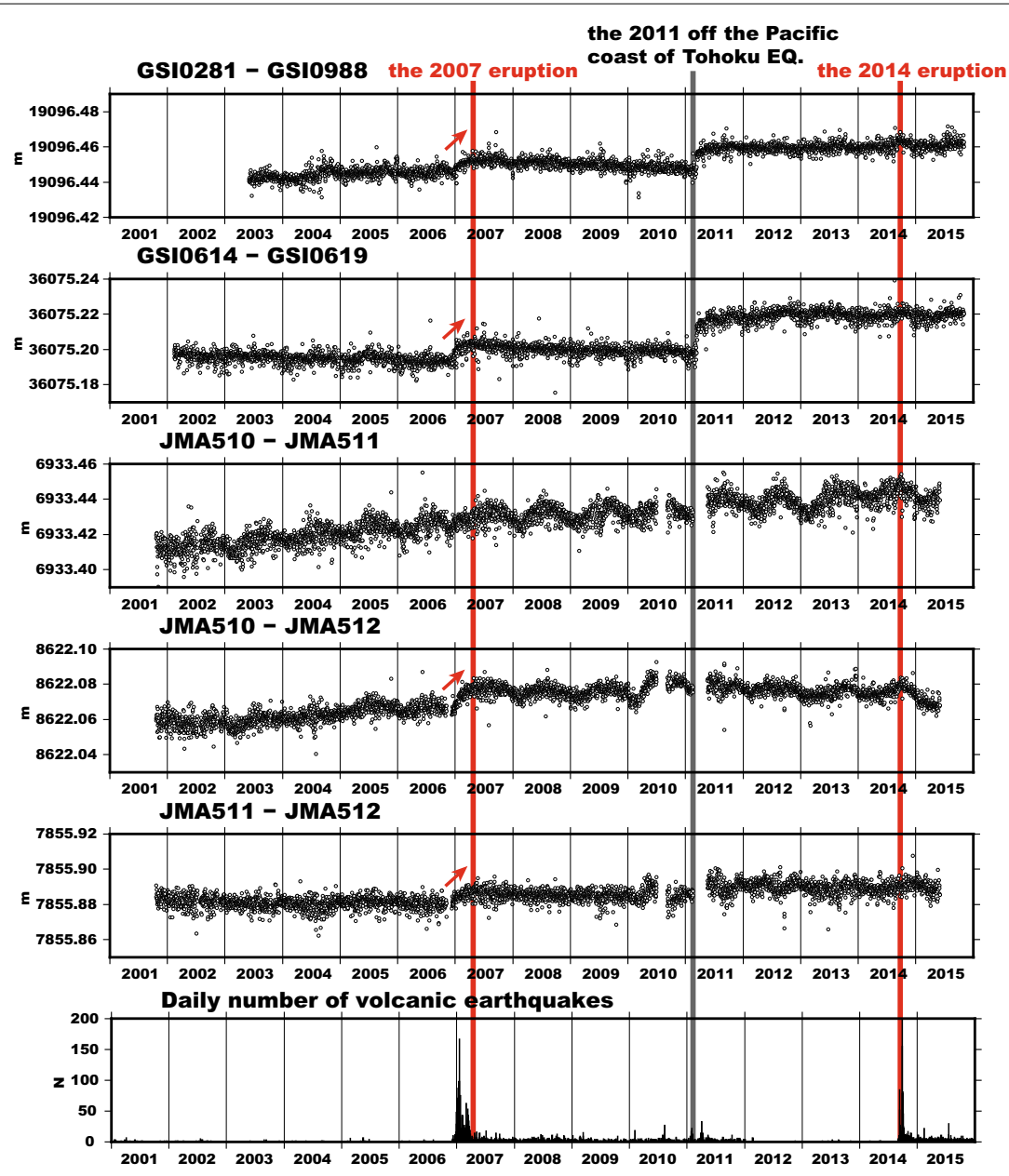

Fig. 2 Time series of the baseline lengths of GNSS stations around Mt. Ontake (see Fig. 1 for station locations and Fig. 3 for baselines) and daily number of volcanic earthquakes. The times of the 2007 and 2014 eruptions of Mt. Ontake and the 2011 off the Pacific coast of Tohoku Earthquake are shown with vertical bars. Records are uncorrected for the coseismic effect. Some records have seasonal noises 


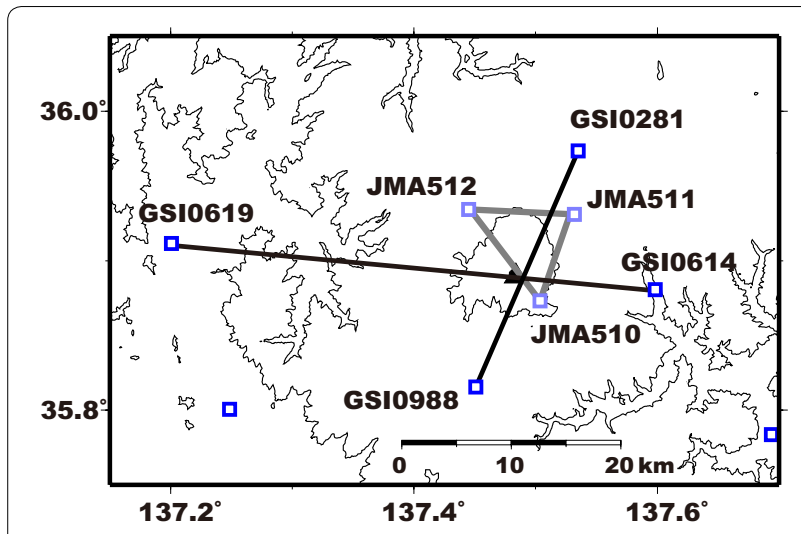

Fig. $\mathbf{3}$ Topographic map showing the baselines on Mt. Ontake for which time series of baseline lengths are shown in Fig. 2 the baselines show extension just before the 2007 eruption. Miyaoka and Takagi (2016) also reported small baseline extensions before the 2014 eruption by the stacking method.

In 2007, a very small phreatic eruption, which had a volcanic eruption index (VEI) of 0 , was estimated to have occurred at the end of March, after which a field survey was conducted on and around the summit of Mt. Ontake (Volcanology Division, JMA 2008). From November 2006 to January 2007, just before the eruption, the area around Mt. Ontake was seismically active, and extensional ground deformation was detected at the same time (Fig. 4). Baselines increased by up to $2 \mathrm{~cm}$ in this period. The changes in the two baselines that included highaltitude site JMA510 (2196 m), JMA510-JMA511 and JMA510-JMA512, appeared to coincide with a seasonal

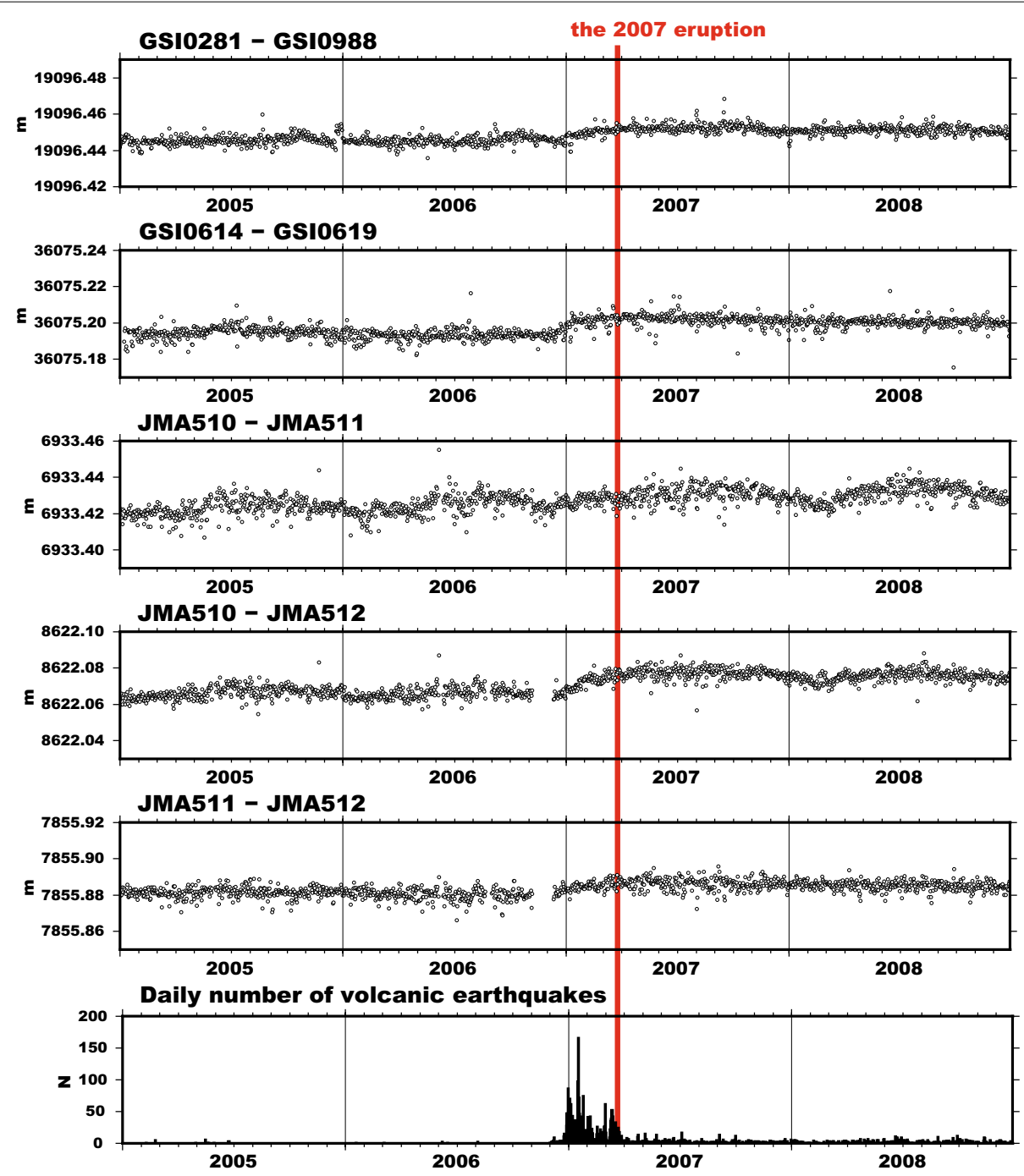

Fig. 4 Time series of lengths of baselines around Mt. Ontake and daily number of volcanic earthquakes from 2005 to 2008 . Extensional ground deformation was detected with active seismic activity just before the 2007 eruption 
phase of contraction from November to February (Figs. 2, 4). Nevertheless, the baseline lengths recorded extension of up to $2 \mathrm{~cm}$ before the 2007 eruption, which means that the extension may have been underestimated.

Figure 5a shows horizontal displacement vectors of the GNSS stations. Each vector was derived from the difference between the averaged coordinate from November $1-30,2006$, and the one from January 21-31, 2007. The displacements at the GEONET stations more distant from Mt. Ontake during this period were dominantly eastward and westward. Therefore, we modeled the pressure source from the GEONET data alone as an open-crack fault (Okada 1992). By using the horizontal displacements of 13 GNSS stations within a $15-\mathrm{km}$ radius of the volcano and fixing GSI0609 for calculation, we estimated that the opencrack fault had an optimal horizontal position beneath the summit, a north-south strike, a depth of $5 \mathrm{~km}$ below sea level at its top, and a volume change of $5.5 \times 10^{6} \mathrm{~m}^{3}$ (Fig. 5a). However, this pressure source did not explain the displacement pattern of the JMANET stations near the volcano. Thus, we reconciled all station data by adding a small spherical pressure source (Mogi 1958) just beneath the summit, at sea level, with a volume change of $0.32 \times 10^{6} \mathrm{~m}^{3}$ (Fig. $5 \mathrm{~b}$ ). However, the volume change may be underestimated to the degree that the extension of baselines around the volcano was underestimated; therefore, this figure is considered to be a minimum value.

Source parameters were calculated by an inversion analysis using the formulas of Mogi (1958) and Okada (1992) and assuming an analytical region consisting of an elastic half-space. However, given the rugged topography, there are large differences of elevation among the GNSS stations. Therefore, we set the boundary of the elastic half-space at the height of each GNSS station for a more accurate approximation of the pressure source.

On volcanoes, as in other precipitous areas, surface displacement due to pressure changes of underground sources can be affected by topography (Meteorological Research Institute 2008), and ground deformation cannot always be explained by an approximate analytic solution. To check the effect of topography, we calculated the displacement of the three JMANET stations, given our estimated source parameters, using the finite element method (FEM) and a digital elevation model (DEM). The

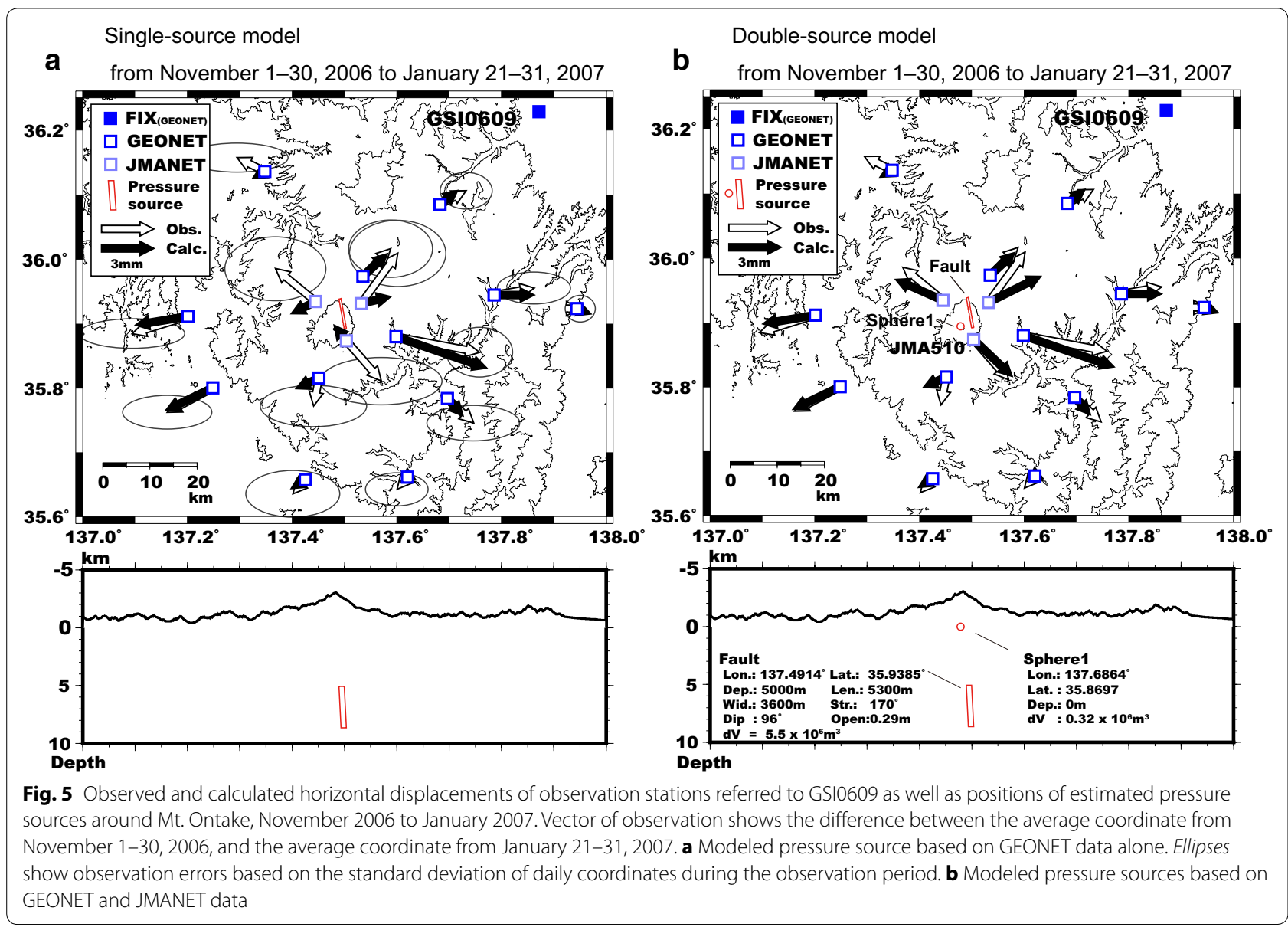


resulting displacement was only as much as $9 \%$ greater than the displacement yielded by the approximate analytic solution. Therefore, in the analysis area of this study, the effect of topography on the source estimation is negligible compared with observation errors.

Scheduled biennial GNSS survey campaigns around the summit were carried out in August 2005 and September 2007. We analyzed the changes in these geodetic positions at five sites with respect to JMANET station JMA510 and found evidence of regional extensional ground deformation in the summit area. We accounted for this deformation with a shallow spherical pressure source at $1700 \mathrm{~m}$ above sea level $(1000 \mathrm{~m}$ below the surface) with a volume change of $0.28 \times 10^{6} \mathrm{~m}^{3}$. This position is just beneath the Jigokudani valley southsouthwest of the summit (Fig. 6), where volcanic vents were active during the 1979 phreatic eruption (VEI 2), the first eruption in recorded history. The 2007 eruption was so small that it was not recorded visually; however, it appears that the eruption reactivated a vent of the 1979 eruption because no new vents were identified in the

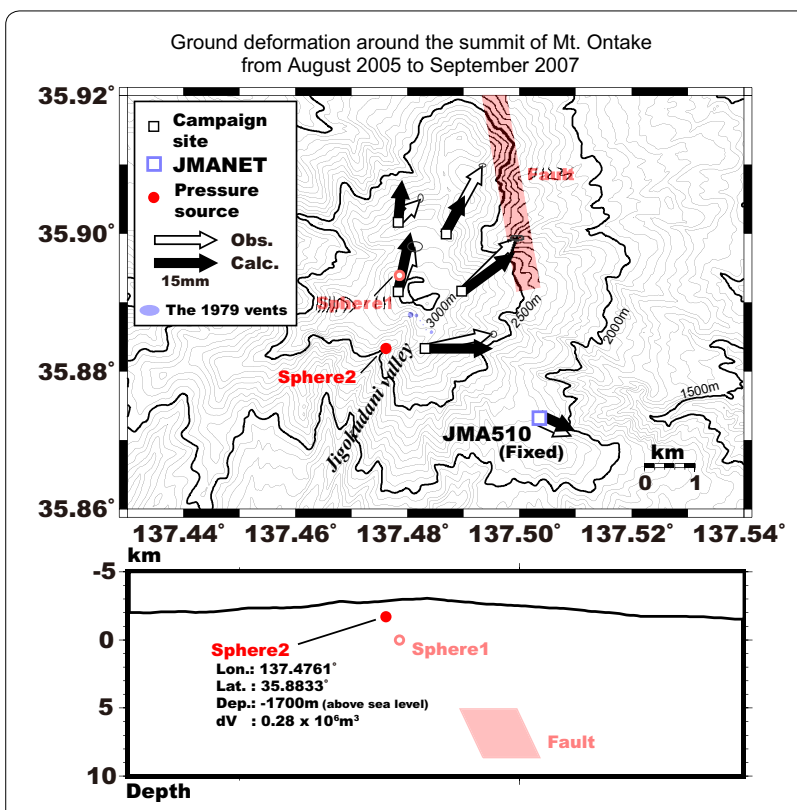

Fig. 6 Observed and calculated horizontal displacements of observation stations referred to JMA510 and positions of estimated pressure sources (Sphere2) based on GNSS campaign data from August 2005 and September 2007. Vector of observation shows the difference between the average coordinate from August 16-19, 2005, and the average coordinate from September 18-21, 2007. Ellipses show observation errors based on the standard deviation of daily coordinates during the observation period. The displacement pattern with addition of the shift of JMA510 is shown for easier understanding. Light red symbols (Sphere1 and Fault) show pressure sources estimated in Fig. 5b. Light blue dots near the summit show vents generated by the 1979 eruption subsequent field survey. Therefore, we consider this inflation source to be the source of the 2007 eruption.

\section{Ground deformation associated with the 2014 eruption}

GNSS network data show that the ground deformation before the 2014 eruption (Fig. 2) was too small for the pressure source to be modeled by the usual method (Miyaoka and Takagi 2016). However, a JMA tiltmeter in a borehole at site JMA510 detected ground tilt changes before and after the 2014 phreatic eruption, which started on September 27, 2014, at 11:52 Japan local time. The pendulum tiltmeter had operated at the bottom of a 100-m-deep borehole, and 1-Hz sampling data had been transmitted to the headquarters of JMA since 2010 (Volcanology Division, JMA 2014).

This tiltmeter record required us to correct mechanical step noises by joining values before and after every step, after which we corrected the effect of solid earth tides by using BAYTAP-G (Tamura et al. 1991) and then made a rainfall correction (Kimura et al. 2015) to create a clean record of tilt changes (Fig. 7a). This record showed that ground tilt with a northwest-upward orientation started on September 27, 2014, at 11:45:10 (7 min before the eruption) and that uplift then continued at an accelerating rate (Fig. 7c), signifying inflation of the summit area. The tilt reached a maximum of $1.92 \times 10^{-6}$ radians (EW component, $0.64 \times 10^{-6}$ radians; NS component, $-1.81 \times 10^{-6}$ radians) at the time when the eruption started at 11:52. The tilt movement then reversed and decreased exponentially. By the middle of October, about 20 days later, the tiltmeter had returned to its state before the eruption (Fig. 7b), signifying that the pressure beneath the summit had returned to its level before the eruption. During the same post-eruption period, the daily number of earthquakes around the volcano returned to its level before the eruption (Fig. 7b).

The orientation of the uplift and subsidence coincides with the alignment of the volcanic vents in the Jigokudani valley (Fig. 8). In addition, the area of uplift overlaps the location of the shallow pressure source estimated from the campaign GNSS data before and after the 2007 eruption.

It is difficult to estimate possible long-term precursory tilt changes before the $2014 \mathrm{Mt}$. Ontake eruption. There may have been gradual northwest-upward tilt in the months before the eruption. However, the tiltmeter record may also include noise due to groundwater fluctuations and snowmelt.

A broadband seismometer operated by Nagano Prefecture at location MIT (Fig. 8), $3 \mathrm{~km}$ from the summit, recorded ground motions (Maeda et al. 2015). We 


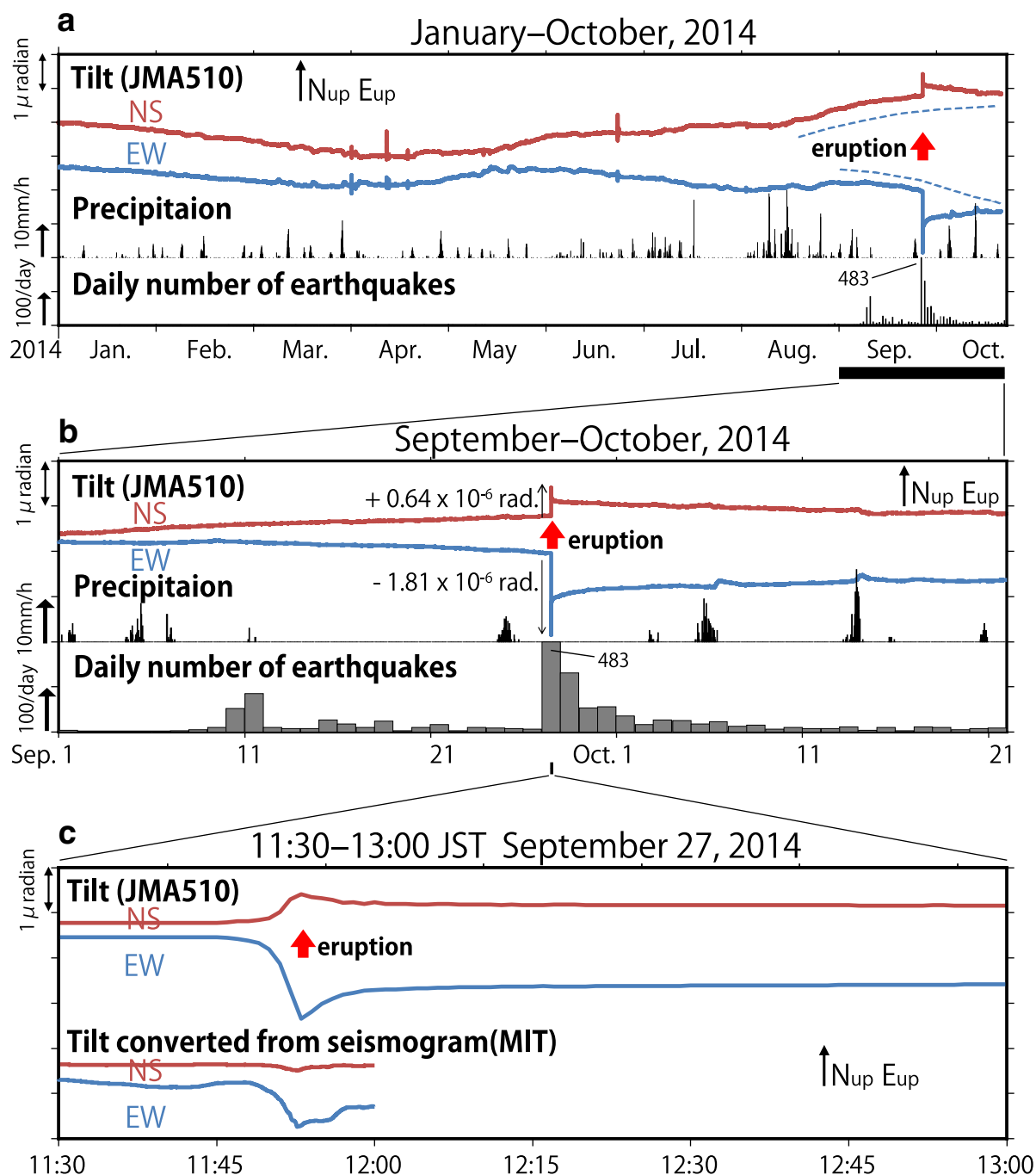

Fig. 7 Time series of tiltmeter and precipitation data at station JMA510 and daily number of volcanic earthquakes. a January-October 2014. b September-October 2014. c Times series of tiltmeter data at JMA510 and the ground tilt converted from the broadband seismogram recorded at MIT (see Fig. 8), operated by Nagano Prefecture, 11:30-13:00 September 27, 2014. Ground tilt started on September 27, 2014, at 11:45:10 JST (7 min before the eruption), and uplift continued at an accelerating rate, signifying inflation of the summit area. Tilt reached a maximum at the time when the eruption started at 11:52. The tilt movement then reversed and decreased exponentially

converted this seismic record to ground tilt by numerical integration (Aoyama and Oshima 2015). The result showed uplift oriented west-southwest (NS component, $-0.11 \times 10^{-6}$ radians; EW component, $-0.94 \times 10^{-6}$ radians), which is the direction toward the summit. This tilt change is shown in Fig. 7c. The orientation of the uplift does not coincide exactly with the alignment of the volcanic vents in the Jigokudani valley, but it does coincide roughly with it (Fig. 8).

We carried out GNSS campaign surveys of the summit area in September 2011 and in October 2015, after the eruption. Because the results included aftereffects of the 2011 off the Pacific coast of Tohoku Earthquake, it was difficult to estimate how much of the deformation was 


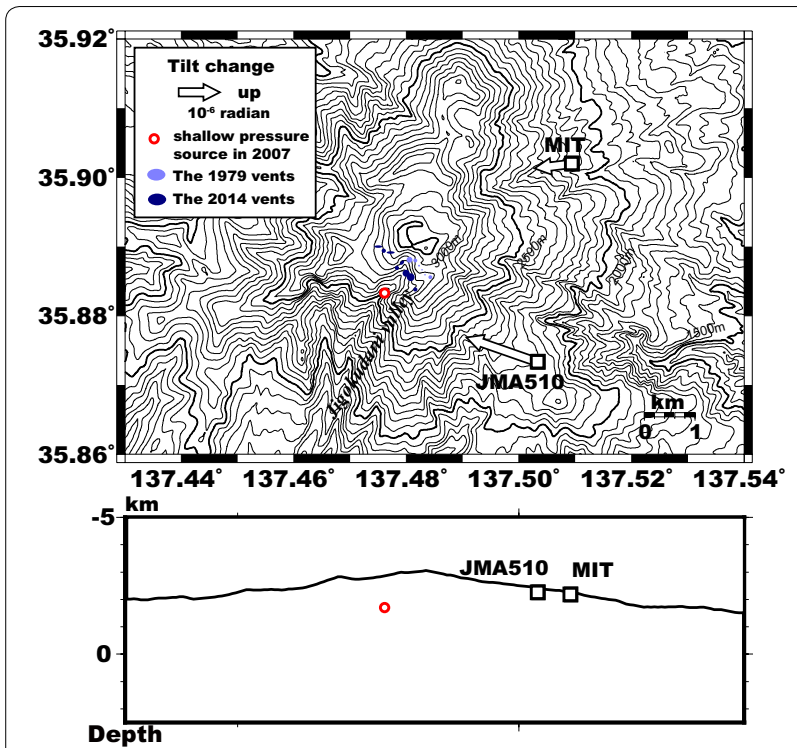

Fig. 8 Ground tilt observed for the 7 min immediately before the 2014 eruption. The circle shows the pressure source estimated with campaign GNSS data (Sphere2 in Fig. 6). Light blue dots show vents generated by the 1979 eruption, and navy blue dots show vents by the 2014 eruption

volcanic, but volcanic regional deformation cannot be ruled out in the summit area.

\section{Discussion}

We infer the following record of pressure sources accompanying ground deformation associated with the 2007 and 2014 eruptions of Mt. Ontake.

GNSS observations suggest that an open-crack fault pressure source deeper than $5 \mathrm{~km}$ below sea level and a spherical shallow pressure source at sea level inflated gradually starting 3 months before the 2007 eruption. The volume changes were $5.5 \times 10^{6}$ and $0.32 \times 10^{6} \mathrm{~m}^{3}$, respectively. The volume change of the deep source was large, so it was likely a dike-type magma chamber. Murase et al. (2016) also suggested the tensile crack model from precise leveling measurements. At the same time, the shallow source was located at the hypocenter of the very long-period seismic event associated with the 2007 eruption (Nakamichi et al. 2009).

An additional, shallower source, $1700 \mathrm{~m}$ above sea level, inflated with a volume increase of $0.28 \times 10^{6} \mathrm{~m}^{3}$ between August 2005 and September 2007. There were no tiltmeter data for this period.
Miyaoka and Takagi (2016) showed that the 2014 eruption was preceded by slight inflation of a deep pressure source at unspecified depth, beginning less than 1 month before the eruption. They did not discuss a shallower source. However, tiltmeter data show that the summit area began tilting upward $7 \mathrm{~min}$ before the eruption and then reversed direction when the eruption began. We interpret this change as having been caused by a shallow pressure source.

From these observations, we can infer that magma filled a chamber below sea level and caused subsurface hydrothermal activity just before the 2007 eruption. A shallower source, $1700 \mathrm{~m}$ above sea level, also inflated and caused a small phreatic eruption. Inflation of this shallower source ceased until the following GNSS campaign survey of 2007. Subsurface hydrothermal activity probably remained high after 2007. The GNSS observations indicate that deep magma migration was not associated directly with the 2014 eruption, but that existing magma under the volcanic edifice reactivated the shallower hydrothermal source that was responsible for the 2007 eruption and subsequently led to regional ground deformation. This shallow source caused the phreatic eruption of September 27, 2014. These inferences are consistent with the groundwater pressure observation (Koizumi et al. 2016). Assuming that this source is located at the 2007 shallower source, the volume change of the Mogi source is estimated to be $0.38 \times 10^{6} \mathrm{~m}^{3}$ from the tilt change just before the eruption.

The 2007 GNSS campaign survey data show that the volume change of the shallower source was $0.28 \times 10^{6} \mathrm{~m}^{3}$. Maeno et al. (2016) estimated that the 2014 eruption produced $0.3-0.5 \times 10^{6} \mathrm{~m}^{3}$ DRE of eruptive products. The volume change just before the 2014 eruption estimated from the tiltmeter data, $0.38 \times 10^{6} \mathrm{~m}^{3}$, is consistent with the estimated amount of eruptive products.

This scenario of pressure sources associated with the 2007 and 2014 Mt. Ontake eruptions is shown schematically in Fig. 9.

\section{Conclusions}

Ground deformation data from Mt. Ontake around the 2007 and 2014 eruptions reveal details of the pressure sources beneath the volcano. GNSS network observations suggest that volume changes before and after the 2007 eruption totaled $6 \times 10^{6} \mathrm{~m}^{3}$, of which $5.5 \times 10^{6} \mathrm{~m}^{3}$ was in an open-crack fault and $0.32 \times 10^{6} \mathrm{~m}^{3}$ was in a shallower sphere below sea level. GNSS campaign survey data 


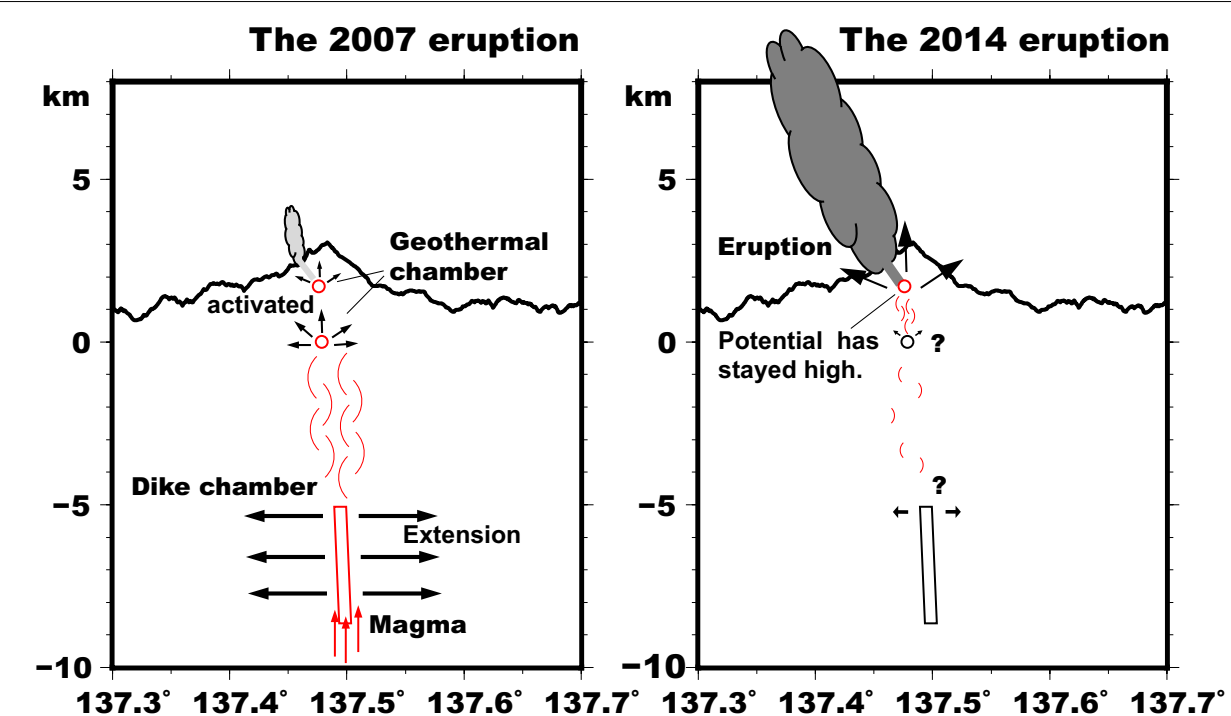

Fig. 9 Schematic diagram showing the pressure sources estimated from ground deformation associated with the 2007 and 2014 Mt. Ontake eruptions. The 2007 eruption was activated by deep magma migration. The potential for subsurface hydrothermal activity remained high from 2007

suggest a volume change of $0.28 \times 10^{6} \mathrm{~m}^{3}$ in a shallow source, $1700 \mathrm{~m}$ above sea level, just beneath the volcanic vents.

In the 2014 eruption, volume change at depth was very small; however, tiltmeter data suggest that a shallow source inflated $7 \mathrm{~min}$ before the eruption with a volume change of $0.38 \times 10^{6} \mathrm{~m}^{3}$.

\section{Authors' contributions}

AT analyzed the GNSS data, estimated pressure models, and drafted this manuscript. SO carried out a portion of the quantitative analysis and discussed the volcanic activity and estimated models. Both authors read and approved the final manuscript.

\section{Acknowledgements}

We thank GSI for furnishing the GEONET GNSS data. We thank the government of Nagano Prefecture for the use of the broadband seismometer data. We are grateful to Makoto Miyashita, Hideki Kojima, Yasushi Ikeda, Tadayoshi Ueno, and Keita Torisu for their help with the GNSS surveys. Most of the figures were prepared using Generic Mapping Tools (Wessel and Smith 1998). Calculations for locating pressure sources were done using MaGCAP-V software, developed by the Meteorological Research Institute (Fukui et al. 2013). We thank two anonymous reviewers and Dr. Koshun Yamaoka, the editor, for their useful comments and suggestions. This work was supported by KAKENHI Grant-inAid for Special Purposes, Grant Number 26900002 of the Japan Society for the Promotion of Science.

\section{Competing interests}

Both authors declare that they have no competing interests.

Received: 9 March 2016 Accepted: 20 July 2016

Published online: 29 July 2016

\section{References}

Aoyama H, Oshima H (2015) Precursory tilt changes of small phreatic eruptions of Meakan-dake volcano, Hokkaido, Japan, in November 2008. Earth Planets Space 67:119. doi:10.1186/s40623-015-0289-9
Dach R, Hugentobler U, Fridez P, Meindl M (2007) Bernese GPS software version 5.0. Astronomical Institute, University of Bern, Bern

Fukui K, Ando S, Fujiwara F, Kitagawa S, Kokubo K, Onizawa S, Sakai T, Shimbori T, Takagi A, Yamamoto T, Yamasato H, Yamazaki A (2013) MaGCAP-V: a Windows-based software to analyze ground deformation and geomagnetic change in volcanic areas. IAVCEI 2013 Abstract, 4W 2C-P8

Kimura K, Tsuyuki T, Suganuma I, Hasegawa H, Misu H, Fujita K (2015) Rainfall correction of volumetric strainmeter data by tank models. Q I Seismol 78:93-158 (in Japanese, with English abstract)

Koizumi N, Sato T, Kitagawa Y, Ochi T (2016) Groundwater pressure changes and crustal deformation before and after the 2007 and 2014 eruptions of Mt. Ontake. Earth Planets Space 68:48. doi:10.1186/s40623-016-0420-6

Maeda Y, Kato A, Terakawa T, Yamanaka Y, Horikawa S, Matsuhiro K, Okuda T (2015) Source mechanism of a VLP event immediately before the 2014 eruption of Mt. Ontake, Japan. Earth Planets Space 67:187. doi:10.1186/ s40623-015-0358-0

Maeno F, Nakada S, Oikawa T, Yoshimoto M, Komori J, Ishizuka Y, Takeshita Y, Shimano T, Kaneko T, Nagai M (2016) Reconstruction of a phreatic eruption on 27 September 2014 at Ontake volcano, Central Japan, based on proximal pyroclastic density current and fallout deposits. Earth Planets Space 68:82. doi:10.1186/s40623-016-0449-6

Meteorological Research Institute (2008) Studies on evaluation method of volcanic activity. Technical Reports of the Meteorological Research Institute, vol 53, pp 23-34. doi:10.11483/mritechrepo.53 (in Japanese, with English captions)

Meteorological Research Institute (2016) The eruption cloud echo from Mt. Ontake on September 27, 2014 observed by weather radar network. Report of Coordinating Committee for Prediction of Volcanic Eruption, vol 119, pp 76-81 (in Japanese, with English captions)

Miyaoka K, Takagi A (2016) Detection of crustal deformation prior to the 2014 Mt. Ontake eruption by the stacking method. Earth Planets Space 68:60 doi:10.1186/s40623-016-0439-8

Mogi K (1958) Relations between the eruptions of various volcanoes and the deformations of the ground surface around them. Bull Earthq Res Inst Univ Tokyo 36:99-134

Murase M, Kimata F, Yamanaka Y, Horikawa S, Matsuhiro K, Matsushima T, Mori H, Ohkura T, Yoshikawa S, Miyajima R, Inoue H, Mishima T, Sonoda T, Uchida K, Yamamoto K, Nakamichi H (2016) Preparatory process preceding the 2014 eruption of Mount Ontake volcano, Japan: insights from precise leveling measurements. Earth Planets Space 68:9. doi:10.1186/ s40623-016-0386-4 
Nakagawa H, Toyofuku T, Kotani K, Miyahara B, Iwashita C, Kawamoto S, Hatanaka Y, Munekane H, Ishimoto M, Yutsudo T, Ishikura N, Sugawara Y (2009) Development and validation of GEONET new analysis strategy (version 4). J Geospatial Inf Auth Japan 118:1-8 (in Japanese)

Nakamichi H, Kumagai H, Nakano M, Okubo M, Kimata F, Ito Y, Obara K (2009) Source mechanism of very-long-period event at Mt. Ontake, central Japan: response of a hydrothermal system to magma intrusion beneath the summit. J Volcanol Geotherm Res 187:167-177

Okada Y (1992) Internal deformation due to shear and tensile faults in a halfspace. Bull Seism Soc Am 82:1018-1040

Takagi A (2013) Ground deformation prior to the 2011 Shinmoedake eruption Technical Reports of the Meteorological Research Institute, vol 69, pp 146-151. http://www.mri-jma.go.jp/Publish/Technical/DATA/ VOL_69/5_2-2.pdf (in Japanese, with English captions)

Tamura Y, Sato T, Ooe M, Ishiguro M (1991) A procedure for tidal analysis with a Bayesian information criterion. Geophys J Int 104:507-516
Volcanology Division, JMA (2008) Volcanic Activity of Ontakesan from March 2007 to June 2007. Report of Coordinating Committee for Prediction of Volcanic Eruption, vol 97, pp 14-29. http://www.data.jma.go.jp/svd/vois/ data/tokyo/STOCK/kaisetsu/CCPVE/Report/097/kaiho_097_06.pdf (in Japanese, with English captions)

Volcanology Division, JMA (2014) Installation of new volcano monitoring systems for 47 volcanoes in Japan. Q J Seismol 77:241-310. http://www. jma.go.jp/jma/kishou/books/kenshin/vol77p241.pdf (in Japanese, with English abstract)

Wessel P, Smith WHF (1998) New, improved version of Generic Mapping Tools released. EOS Trans AGU 79:579. doi:10.1029/98EO00426

Yoshida Y, Funakoshi M, Nishida M, Ohmi K, Takagi A, Ando S (2012) Crustal Deformation observed by GPS around Azuma Volcano. Q I Seismol 76:1-8 (in Japanese, with English abstract and captions)

\section{Submit your manuscript to a SpringerOpen ${ }^{\circ}$ journal and benefit from:}

- Convenient online submission

- Rigorous peer review

- Immediate publication on acceptance

- Open access: articles freely available online

- High visibility within the field

- Retaining the copyright to your article 